Case Reports in
Gastroenterology
Case Rep Gastroenterol 2021;15:137-141

DOI: 10.1159/000511751

Published online: February 3, 2021

(c) 2021 The Author(s)

Published by S. Karger AG, Basel

www.karger.com/crg

This article is licensed under the Creative Commons Attribution-NonCommercial 4.0 International License (CC BY-NC) (http://www.karger.com/Services/OpenAccessLicense). Usage and distribution for commercial purposes requires written permission.

\title{
Endoscopic Removal of a Press-Through Pack from the Anal Canal
}

\author{
Ayaka Takasu Takashi Ikeya Katsuyuki Fukuda \\ Department of Gastroenterology, St. Luke's International Hospital, Tokyo, Japan
}

\section{Keywords}

Press-through pack · Endoscopy · Anal canal

\begin{abstract}
The incidence of press-through pack (PTP) ingestion has been increasing. In many cases, the ingested PTP is lodged in the esophagus. Here, we report a case of endoscopic removal of a PTP from the anal canal. An 89-year-old man with mild dementia presented with a 3-day history of anal pain. On digital rectal examination, we felt a hard and sharp object, which could not be manually removed due to its shape. Therefore, it was removed endoscopically. We inserted an endoscope with a large-caliber soft oblique cap and observed the PTP in the anal canal. It was successfully removed using grasping forceps. The patient was stable, with only mild anal fissures, and no serious complications such as perforation and bleeding were observed. It is generally recognized that a PTP that reaches the large intestine is naturally expelled. Even if a PTP could pass through the pylorus or the small intestine, it could still be difficult to discharge naturally from the anus without discomfort or pain, as in this case.
\end{abstract}

(C) 2021 The Author(s)

Published by S. Karger AG, Basel

\section{Introduction}

The press-through pack (PTP), a commonly used packaging for medications, is the most common foreign body (FB) ingested accidentally by older adults, owing to their use of

Ayaka Takasu
Department of Gastroenterology, St. Luke's International Hospital
$9-1$ Akashi-cho, Chuo-ku
Tokyo 104-8560 (Japan)
takasuay@luke.ac.jp




\section{Case Reports in Gastroenterology}

Case Rep Gastroenterol 2021;15:137-141 DOI: $10.1159 / 000511751$

(c) 2021 The Author(s). Published by S. Karger AG, Basel www.karger.com/crg

Takasu et al.: Endoscopic Removal of a Press-Through Pack from the Anal Canal

medications for different pathologies [1]. With the rapid increase in the elderly population in Japan, the incidence of PTP ingestion has been increasing. In most cases the ingested PTP was lodged in the esophagus, and in a few cases it reached the lower gastrointestinal tract. Moreover, it is generally believed that PTPs that reach the colon beyond a narrow area, such as the pylorus or small intestine, are naturally excreted through the anus. Here, we report a case of endoscopic removal of a PTP from the anal canal.

\section{Case Presentation}

An 89-year-old man presented with a 3-day history of anal pain. He had mild dementia, benign prostatic hyperplasia, and chronic gastritis for which he was taking multiple medicines. He had felt anal discomfort 3 days prior which gradually worsened and became painful. He felt a sharp, hard object in his anus, but could not remove it on his own due to pain.

The patient's vital signs on presentation were stable. Physical examination showed that his abdomen was soft and without tenderness. No remarkable findings were observed in his anus. On digital rectal examination, we felt something hard and sharp. An attempt to remove it manually failed due to its shape and the patient's pain. At this time, a FB in the anal canal was suspected and we decided to remove it endoscopically.

An endoscope (GIFQ260J; Olympus, Tokyo, Japan) was inserted transanally with the patient in a left lateral decubitus position. A reticulated and sharp object was observed. Although its identity was unclear, the endoscope was removed to avoid causing mucosal damage. We attached a large-caliber soft oblique cap to the tip of the endoscope and inserted it a second time. A PTP lodged in the anal canal was observed (Fig. 1). The PTP was moved into the cap using grasping forceps; it was successfully removed (Fig. 2, 3). There were mild fissures, but no major complications such as perforation or bleeding were observed.

\section{Discussion and Conclusion}

In general, accidentally ingested FBs are expelled from the anus without causing any symptoms, and $<1 \%$ of them cause complications, such as perforation and peritonitis [2]. However, the ingestion of sharp and pointed objects, such as animal/fish bones, needles, and PTPs, increases the risk of perforation or obstruction by as much as 35\% [3]. Therefore, they should be removed within $24 \mathrm{~h}$ [4].

The PTP, one of the most commonly ingested FBs, is commonly used in Japan [1] and Korea [5] for the packaging of medications and is ingested mostly by elderly people. The number of reports of FBs in the gastrointestinal tract due to PTP ingestion has been increasing [6]. It has been reported that ingested PTPs are found in the esophagus in approximately $90 \%$ of patients due to the physiological structure of the esophagus [7], with a few cases having reportedly reached the lower gastrointestinal tract. Early endoscopic removal is recommended for patients who have ingested PTPs, as mentioned above. It is not known how many PTPs beyond the pylorus are spontaneously expelled from the anus. However, there have been a few case reports of small bowel perforation [8], obstructive ileus [9], or colonic diverticulum perforation [10]. Therefore, it was considered that PTPs that could pass the pylorus or reach the lower gastrointestinal tract should similarly be carefully followed and removed with an endoscope if possible.

\section{Karger'=}




\section{Case Reports in Gastroenterology}

We report a rare case of an ingested PTP lodged in the anal canal, which was safely removed with an endoscope. The number of patients ingesting PTPs is expected to increase as the population ages. Although there were no complications, such as bleeding or perforation of the anus, due to PTP ingestion in this case, it emphasizes the importance of ascertaining that PTPs passing beyond the narrow sections of the pylorus, small intestine, and Bauhin's valve could still be difficult to discharge from the anus eventually. This causes symptoms such as anal discomfort, and endoscopic removal could be an option for removing the PTP from the anal canal.

\section{Statement of Ethics}

The patient provided written informed consent for publication of this case report, including images.

\section{Conflict of Interest Statement}

The authors have no conflicts of interest to declare.

\section{Funding Sources}

No funding was obtained for this study.

\section{Author Contributions}

A. Takasu planned and designed this report, collected and analyzed the data, and drafted the article. T. Ikeya and K. Fukuda interpreted the data and critically revised the manuscript. All authors approved the submitted version of the manuscript.

\section{References}

1 Limpias Kamiya KJ, Hosoe N, Takabayashi K, Hayashi Y, Sun X, Miyanaga R, et al. Endoscopic removal of foreign bodies: A retrospective study in Japan. World J Gastrointest Endosc. 2020 Jan;12(1):33-41.

2 Birk M, Bauerfeind P, Deprez PH, Häfner M, Hartmann D, Hassan C, et al. Removal of foreign bodies in the upper gastrointestinal tract in adults: European Society of Gastrointestinal Endoscopy (ESGE) Clinical Guideline. Endoscopy. 2016 May;48(5):489-96.

3 Kao LS, Nguyen T, Dominitz J, Teicher HL, Kearney DJ. Modification of a latex glove for the safe endoscopic removal of a sharp gastric foreign body. Gastrointest Endosc. 2000 Jul;52(1):127-9.

4 Eisen GM, Baron TH, Dominitz JA, Faigel DO, Goldstein JL, Johanson JF, et al.; American Society for Gastrointestinal Endoscopy. Guideline for the management of ingested foreign bodies. Gastrointest Endosc. 2002 Jun;55(7):802-6.

5 Seo YS, Park JJ, Kim JH, Kim JY, Yeon JE, Kim JS, et al. Removal of press-through-packs impacted in the upper esophagus using an overtube. World J Gastroenterol. 2006 Sep;12(36):5909-12.

6 Sudo T, Sueyoshi S, Fujita H, Yamana H, Shirouzu K. Esophageal perforation caused by a press through pack. Dis Esophagus. 2003;16(2):169-72.

\section{Karger'"}




\section{Case Reports in Gastroenterology}

\begin{tabular}{l|l}
\hline Case Rep Gastroenterol 2021;15:137-141 \\
\hline DOI: 10.1159/000511751 & $\begin{array}{l}\text { @ 2021 The Author(s). Published by S. Karger AG, Basel } \\
\text { www.karger.com/crg }\end{array}$ \\
\hline Takasu et al.: Endoscopic Removal of a Press-Through Pack from the Anal Canal
\end{tabular}

7 Ikenberry So, Jue TL, Anderson MA, Appalaneni V, Banerjee S, Ben-Menachem T, et al.; ASGE Standards of Practice Committee. Management of ingested foreign bodies and food impactions. Gastrointest Endosc. 2011 Jun;73(6):1085-91.

8 Hashizume T, Tokumaru AM, Harada K. Small intestine perforation due to accidental press-through package ingestion in an elderly patient with Lewy body dementia and recurrent cardiopulmonary arrest. BMJ Case Rep. 2015 Dec;2015:bcr2015212723.

9 Imaizumi H, Yamauchi M, Namiki A, Takahashi H, Hatakeyama K. Obstructive ileus caused by a swallowed foreign body (a "press-through" package) and preexisting adhesions. Am J Emerg Med. 1997 Jan;15(1):52-3.

10 Fujii K, Nitta T, Kawasaki H, Kataoka J, Ishibashi T. A case of sigmoid colon perforation caused by accidental ingestion of a press-through package. Nippon Daicho Komonbyo Gakkai Zasshi. 2015 Apr;68(3):163-7.

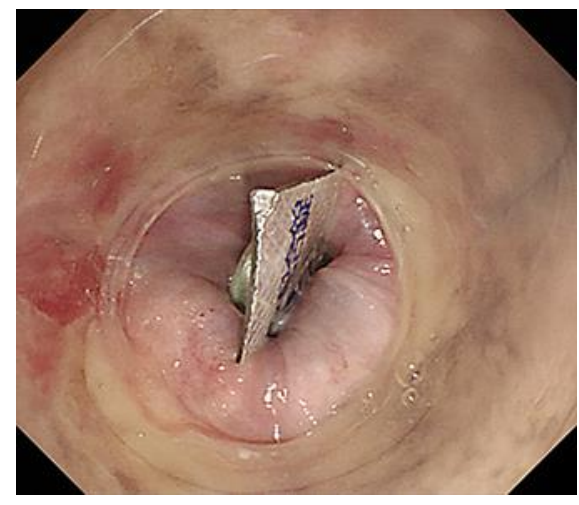

Fig. 1. The press-through pack lodged in the anal canal as observed through the endoscope.

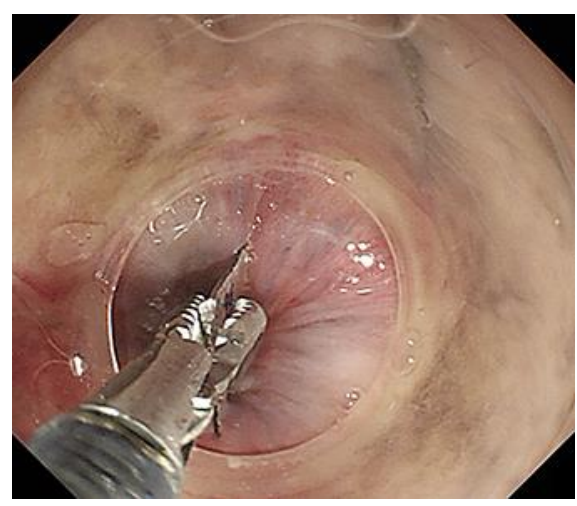

Fig. 2. Removal of the press-through pack using grasping forceps as observed through the endoscope. 
Case Reports in Gastroenterology
Case Rep Gastroenterol 2021;15:137-141

DOI: $10.1159 / 000511751$

(c) 2021 The www.karger.com/crg

Takasu et al.: Endoscopic Removal of a Press-Through Pack from the Anal Canal

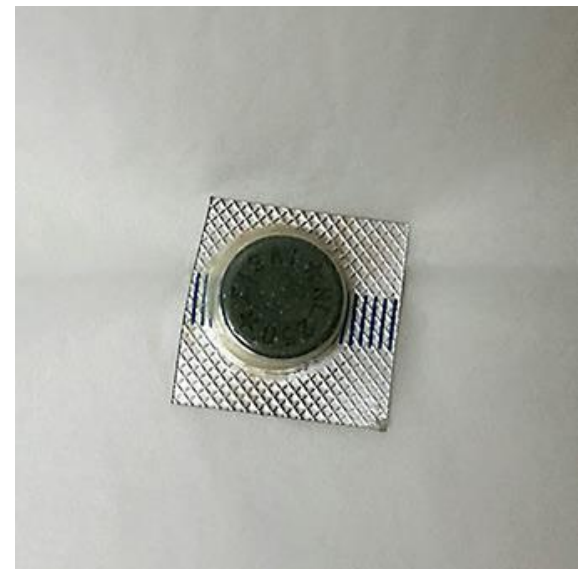

Fig. 3. The press-through pack after removal from the anal canal. 